\title{
DALCROZE E O ENSAIO “OS 'HOP' MUSICAIS" (1930): ALGUMAS CONSIDERAÇÕES PRELIMINARES
}

\section{DALCROZE AND THE ESSAY “LES \\ 'HOP' MUSICAUX" (1930): SOME PRELIMINARY CONSIDERATIONS}

José Rafael Madureira ${ }^{1}$ Universidade Federal dos Vales do Jequitinhonha e Mucuri (UFVJM) joserafaelmadureira@gmail.com 


\section{Resumo}

Tradução do ensaio Les "hop" musicaux (Os "hop" musicais), de autoria de Émile Jaques-Dalcroze e publicado originalmente na revista Le Rythme em 1930. A tradução é precedida por uma apresentação sobre as origens e desdobramentos do "hop" musical, um dos princípios didáticos mais importantes e lúdicos da Rítmica Dalcroze, integrado aos exercícios de solfejo, improvisação e plasticidade viva ("plastique animée"). Ao final do ensaio, para exemplificar o uso do "hop" musical, Dalcroze apresenta um compêndio com 55 exercícios, um valioso material sobre um tema ainda muito pouco estudado no Brasil.

Palavras-chave: Jaques-Dalcroze. Rítmica. Pedagogia musical. Tradução.

\section{Abstract}

Translation of the essay Les "hop" musicaux (The musical "hop"), written by Émile Jaques-Dalcroze and originally published in Le Rythme magazine (1930). The translation is preceded by a presentation on the origins and developments of the musical "hop", one of the most important and ludic didactic principles of Dalcroze Eurhythmics, integrated with exercises in solfeggio, improvisation and living plasticity ("plastique animée"). At the end of the essay, to exemplify the use of the musical "hop", Dalcroze introduce a compendium of 55 exercises, a valuable material on a topic that has not been studied much in Brazil.

Keywords: Jaques-Dalcroze. Eurhythmics. Musical Education. Translation.

\footnotetext{
1 Professor do Departamento de Educação Física da UFVJM (campus Diamantina/MG). Mestre e doutor em Educação, Linguagem e Arte, Licenciatura em Música, Licenciatura em Educação Física, curso técnico-profissional em Educação Musical/Piano e Canto. Realizou estágios internacionais em pedagogia da dança na França, Itália e Alemanha e ensinou em diversas instituições de ensino superior, públicas e privadas, nos cursos de licenciatura em Teatro, licenciatura em Educação Física, licenciatura em Dança e Pedagogia, destacando-se a UFG, UNICAMP e UFAL. É pesquisador-líder do Grupo de Estudos em Métodos e Técnicas de Ensino de Dança, Teatro e Música.
} 
"Hop", na língua francesa, é uma interjeição de advertência que evoca no ouvinte uma reação brusca, um salto, um giro, uma esquiva etc. Embora ausente das gramáticas de língua portuguesa, a expressão não nos é estranha. Desde tempos arcaicos, o sinal "hop" vem sendo vocalizado entre funâmbulos e durante os treinamentos militares. Em meados do século XIX, o "hop" foi incorporado às lições de ginástica e balé clássico.

Pronunciado em voz de comando, o "hop" indica o momento exato para engajar as forças - o denominado timing - e agir. O "hop" garante o sincronismo e a precisão das manobras coletivas, seja nas trocas de claves entre malabaristas, nos exercícios de ordem unida, nos voos dos trapezistas ou na execução de acrobacias.

Dalcroze conheceu o "hop" em suas aulas de ginástica na escola, e colocou-o à prova desde o início de sua carreira como professor de harmonia e solfejo do Conservatório de Genebra numa tentativa de "salvar" os alunos de um fazer mecanizado e ajudá-los a enfrentar os graves problemas auditivo-musicais apresentados.

As primeiras aparições do "hop", no conjunto da obra de Dalcroze, podem ser observadas em alguns exercícios descritos no caderno didático Gymnastique Rythmique - Méthode Jaques-Dalcroze, publicado em 1906. Em Le Rythme, la Musique et l'Éducation, obra capital de Dalcroze publicada em 1920, o “hop" aparece apenas no VI capítulo (La Rythmique, le Solfège et l'Improvisation), indicado como "comandos inesperados" (p. 79).

Somente em 1930, o "hop" - agora qualificado como "musical" - irá ocupar o protagonismo de uma produção. Esse texto, intitulado Les 'hop' musicaux (Os "hop" musicais) e cuja tradução será apresentada em seguida, foi publicado na revista bilingue Le Rythme/Der Rhythmus (O Ritmo), um periódico idealizado por Paul Bœpple em 1908 como um "boletim de correspondência" (Korrespondenzblatt) entre os membros da Sociedade de Ginástica Rítmica - Método Dalcroze, que naquele momento contabilizava 200 associados $^{2}$. No editorial do primeiro número (1909, p. 2), Bœpple explica que o título do "boletim" foi escolhido para lembrar aos leitores que "o ritmo reuniu e agrupou a todos, e é ele quem, doravante, organiza as nossas vidas, rege as nossas vontades e orienta os nossos desejos artísticos".

Ainda que o conceito do "hop" musical estivesse sendo apresentado pela primeira vez, Dalcroze escreve pouco mais de uma página, acrescentando ao final de sua exposição uma lista de exercícios utilizados no Instituto Jaques-Dalcroze de Genebra. Dalcroze considera que essa "breve nomenclatura" seria suficiente para oferecer aos leitores uma ideia clara sobre o "hop" musical. Esses "leitores", evidentemente, eram professores rythmiciens ${ }^{3}$ vinculados ao seu Instituto, do contrário, o entendimento dos exercícios não seria assim tão acessível.

A lista apresentada é organizada em 5 categorias: 1) "dinâmica, agógica e elasticidade" - 13 exercícios; 2) "melodia e harmonia" - 20 exercícios; 3) "rítmica e métrica" - 8

2 Em 1926, devido ao aumento exponencial de seus membros, a Sociedade de Ginástica Rítmica foi substituída pela Union Internationale des Professeurs de la Méthode. Em 1967, foi criada a Fédération Internationale des Enseignants de Rythmique (FIER), em atividade até o presente momento.

3 "Rythmicien" ou "rythmiciènne", na declinação de gênero, é um termo amplamente utilizado por Dalcroze para indicar aqueles que estudam a Rítmica, quais sejam professores ou estudantes. Por não haver um termo compatível em português, optou-se por manter o original. 
exercícios; 4) "timbres" - 6 exercícios; 5) "sensação e análise visual" - 8 exercícios. Os exercícios 4 e 5 desse último grupo articulam a Rítmica aos "jogos de luz" concebidos por Adolphe Appia no Instituto de Hellerau e que foram registrados no manuscrito $L a$ Gymnastique rythmique et la lumière (APPIA, 1932).

O "hop" dalcroziano diferencia-se significativamente do contexto ginástico, militar ou circense, no qual comando é esperado, o que possibilita aos praticantes alguma preparação. Dalcroze (1945, p. 159) esclarece que a finalidade do "hop" é "manter o corpo e a mente sob pressão", embora ele seja "o contrário de um condicionamento". Ademais, o "hop" musical, diversamente do "hop" vocalizado por instrutores de ginástica, requer a presença de um rythmicien.

O "hop" musical constitui-se de indicações auditivo-musicais propostas pelo professor ou por algum aluno-solista que desequilibram o curso dos exercícios corporais. Essas indicações podem ser expressas por alternâncias de compasso, desenhos de fraseado, variações de timbre, mudanças de agógica ou dinâmica, acréscimos de ornamentos ou notas melódicas, execução de cadências ou progressões no campo harmônico etc.

A iminência do "hop" musical mantém os estudantes - crianças, jovens ou adultos - em estado de alerta, pois é preciso estar atento não apenas ao sinal propriamente dito, mas ao fluxo de informações musicais recebidas pelo ouvido para, em seguida, processar os dados e apresentar respostas motoras rápidas e precisas.

Marie-Laure Bachmann (1998, p. 148-9) nos fornece um excelente exemplo ao descrever o tradicional "jogo da cadeira" na perspectiva do "hop" musical. Em sua versão da brincadeira, os jogadores não se sentam quando a música gravada para, pois o sinal para a ocupação das cadeiras é harmônico, produzido "ao vivo" pelo rythmicien sentado ao piano. A proposta de Bachmann, além de promover um verdadeiro despertar auditivo nos alunos, valoriza suas qualidades artístico-musicais e não suas valências físicas.

Dalcroze não descarta os "hop" tradicionais, realizados em voz de comando ou com o auxílio de instrumentos de percussão, mas ele é categórico ao afirmar que a efetivação desse recurso demandaria sinais sonoros mais complexos.

Em algumas sistematizações da Rítmica, os professores empregam como colaborador do movimento corporal a "música" dos instrumentos de percussão. É evidente que os ritmos batidos sobre um timbale, um tambor ou um tamborim são próprios ao desenvolvimento do sentido da acentuação e da percepção métrica, mas estes são apenas alguns dos elementos da música. A continuidade, as superposições, associações e dissociações de melodias e harmonias introduzem no organismo sensivel, efetivamente, um elemento de vida íntima e animação geral que eu penso ser necessário para uma completa educação psicofísica. [...] Os ritmos percutidos incitam impulsos rápidos e flexíveis, mas são os encadeamentos de movimentos ritmados, seu fraseado, suas modificações lentas ou rápidas de expressão, que asseguram sua tripla existência: sensorial, espiritual e sentimental. (Dalcroze apud DUTOIT-CARLIER, 1965, p. 384-5). 
Ao final do texto introdutório, em nota de rodapé, Dalcroze acrescenta uma advertência sobre a falta de compromisso dos professores de Rítmica em divulgar o trabalho por eles realizado nas diversas escolas filiadas ao Instituto de Genebra naquele período (mais de 20 países). De fato, com professores espalhados pelos 5 continentes e sem dispor de um sistema de informação capaz de levantar e processar todos esses dados, era impossível para Dalcroze controlar o que faziam em seu nome. Essa falta de controle o preocupava bastante, o que resultou em mais uma observação, desta vez implacável, publicada na revista Le Rythme alguns anos depois:

\footnotetext{
Por falta de centralização, minhas ideias têm sido frequentemente distorcidas; as imitações abundam, os simulacros multiplicam-se e observamos mestres de dança ou ginástica, totalmente ignorantes dos princípios musicais que formam a base do meu sistema, denominarem-se professores de Rítmica (JAQUES-DALCROZE, 1935, p. 13).
}

Dalcroze recorreu ao "hop" desde suas primeiras lições de música no Conservatório de Genebra. Diante dos excelentes resultados alcançados, o "hop" se tornou um princípio-chave do ensino da Rítmica, integrado aos estudos de solfejo, improvisação e plasticidade viva (Plastique Animée).

Em última análise, o "hop" musical poderia ser imaginado como um princípio estético-pedagógico mais amplo, indicando procedimentos mais lúdicos e criativos de ensino que exigiriam, tanto dos alunos quanto do professor, um estado de cumplicidade e presença.

\section{Referências}

APPIA, A. La Gymnastique rythmique et la lumière [1912], Le Rythme, Genebra, n. 34, dez./1932, p. 15-17.

BACHMANN, Marie-Laure. La Rítmica Jaques-Dalcroze: una educación por la música y para la música. Madrid: Pirámide, 1998.

BCFPPLE, P. Une bonne année à tous nos membres, lecteurs et futurs abonnés (editorial). Le Rythme, Genève, n. 1, 1909, p. 1-3.

DUTOIT-CARLIER, C. L. Jaques-Dalcroze: createur de la Rythmique. In: MARTIN, F. et al. Émile Jaques-Dalcroze: l'homme, le compositeur et le créateur de la Rythmique. Neuchâtel: La Baconnière, 1965, p. 305-412.

JAQUES-DALCROZE, É. Gymnastique Rythmique. Neuchatel: Jobin et Cie., 1906. Le Rythme, la Musique et L'Éducation. Lausanne: Jobin et Cie., 1920. 
La Rythmique, le Solfège et l'Improvisation [1914] In: JAQUES-DALCROZE, É. Le Rythme, la Musique et L'Éducation. Lausanne: Jobin et Cie/Éditions musicales, 1920, p. 74-92.

Les "hops" musicaux. Le Rythme, Genève, n. 28, mar./1930, p. 14-19.

Petite Histoire de la Rythmique. Le Rythme, Genève, n. 39, 1935, p. 3-18.

La Musique et Nous: notes sur notre double vie. Genève: Perret-Gentil,

1945.

MARTIN, F. et al. Émile Jaques-Dalcroze: l'homme, le compositeur et le créateur de la Rythmique. Neuchâtel: La Baconnière, 1965. 


\section{Os "hop" musicais}

Émile Jaques-Dalcroze*

Os "hop" gritados - assim como outras interjeições - não são utilizados somente nas lições de Rítmica, mas em todas as situações da vida cotidiana em que o esforço precisa ser mobilizado e conduzido ao seu máximo e quando o momento de partida do movimento precisa ser indicado com precisão. O uso do "hop" provoca o despertar de movimentos rítmicos, de suas paradas ou modificações, sendo, portanto, de fundamental importância no início dos estudos, momento em que a criança precisa lutar constantemente contra resistências, contra sua desatenção e contra hábitos motores já enraizados. Todavia, tão logo os seus músculos estiverem mais relaxados, quando o seu corpo não manifestar qualquer dificuldade para deslocar o próprio peso com fluidez, quando o seu sistema nervoso estiver fortalecido e regulado, será conveniente substituir o trivial "hop", vociferado ou murmurado, por um comando de caráter mais musical. De fato, o "hop" gritado não precisa se submeter à música a não ser quando o comando precisa ser executado, e mesmo nos casos em que ele obriga o aluno a executar determinado movimento alguns tempos ou compassos depois de ter sido indicado, ele dirige-se à atenção geral do sujeito e às suas faculdades analíticas, não ao seu ouvido musical. A criança, com frequência, revela ser um excelente rythmicien nos momentos em que o "hop" Ihe exige; todavia, muito confiante nas ordens dadas pelo professor, ela não se preocupa em ouvir a música que associa um "hop" ao seguinte, não se submete às suas nuances e nem reconhece os seus acentos. Faz-se necessário, portanto, desde o final do primeiro ciclo de iniciação à Rítmica, substituir os "hop" gritados por comandos de caráter musical. Como resultado imediato desse sistema, a atenção do aluno é necessária e constantemente focada no discurso musical, pois são as suas modificações, acentuações ou interrupções que irão desencadear os diversos movimentos corporais determinados pelo professor.

É bem provável que um número significativo de professores de Rítmica já havia pensado em acrescentar aos seus comandos verbais, apelos sonoros variados, nuançados e recitados que restituiriam a cumplicidade do aluno em relação à música que ele é convocado a interpretar. É certo que, ao agir assim, eles favorecem o despertar e o desenvolvimento da sensibilidade musical da criança, ao passo que, ao conduzir a sequência de seus movimentos com o auxílio de gritos, números ou golpes em um bumbo, o professor produz apenas ginastas e dançarinos da velha escola. Apresento em seguida uma breve nomenclatura de "hop" musicais utilizados em nosso Instituto. Trata-se apenas de alguns exemplos essenciais de indicações gerais que me parecem ser suficientes para oferecer aos leitores uma ideia clara desse tipo de exercício. Ainda há muito a ser descoberto, não resta dúvida, mas eu me permito acreditar que os Rythmiciens que tenham trabalhado na mesma direção que nós empenhar-se-ão para completar essa lista

* Les "hop" musicaux. Le Rythme, Genebra (Suíça), n. 28, mar./1930, p. 14-19. Tradução e notas de José Rafael Madureira. 
e beneficiar, com as suas descobertas, os leitores de Le Rythme*.

\title{
Lista de exercícios conduzidos pelos "hop" musicais:
}

\author{
Dinâmica, agógica, elasticidade
}

1. A cada acorde tocado ao piano, impulso do torso e dos braços. Se o acorde é mantido e continua a ressoar, os braços se detêm; quando o som acaba, os braços repousam.

2. Os alunos caminham em semínimas enquanto durar o ressoar de um acorde. Eles param quando o som é interrompido ou, então, finalizam o compasso com saltitos ${ }^{1}$ [sautillés] ou em colcheias.

3. Os alunos caminham em duas fileiras. O professor, ao piano, toca uma peça a duas vozes, a voz superior em staccato e a segunda voz em legato, ou vice-versa. Uma fileira segue a voz superior e a outra a voz inferior, e ambas mudam o andamento quando o professor inverte as vozes.

4. O pianista toca as colcheias em legato. Quando ele "belisca" 4 colcheias, os alunos caminham em staccato as 4 colcheias seguintes ou executam determinado ritmo. E vice-versa.

5. Caminhamos em colcheias. Um fortissimo súbito conduz uma mudança de métrica. O mesmo depois de um pianíssimo súbito.

6. Um crescendo ou um diminuendo de 4 (ou 6) colcheias produz na colcheia seguinte um gesto, uma batida com os pés, um impulso, um salto, um passo para trás, uma síncope, uma genuflexão ou uma repetição do tema.

7. Dois, três ou quatro acentos sucessivos determinam uma métrica de 2, 3 ou 4 tempos.

\footnotetext{
* Aproveitamos a ocasião para lembrar aos professores de Rítmica que a revista Le Rythme foi criada como espaço de integração entre todos eles. Pois, infelizmente, apesar de todas as nossas constantes solicitações, os professores das escolas de Rítmica filiadas ao nosso Instituto não nos mantém informados de suas experiências e descobertas, prejudicando assim o nosso método e impedindo a divulgação de novos exercícios experimentados por toda parte no "mundo da Rítmica", observando-se que somente um esforço em conjunto poderá garantir a contínua vitalidade do método. Na realidade, o Instituto de Genebra é responsável pela divulgação de todas as matérias publicadas na revista Le Rythme e, portanto, devido à falta de relação entre os estudos realizados em todos os países, ela não poderá desenvolver plenamente o papel para a qual foi criada. Que os professores nos enviem - seremos muito gratos - os relatos regulares de suas atividades e façam a gentileza de nos explicar os novos exercícios inventados e experimentados. Que não tenham receio, pois essa divulgação não irá fazê-los perder a autoria dos exercícios criados. A revista Le Rythme está pronta para batizar esses exercícios com o nome de seus inventores, de modo a possibilitar que eles passem à posteridade! O próximo número de Le Rythme (junho) será consagrado aos relatos das

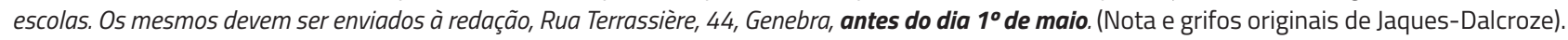
1 No primeiro volume do caderno didático La Rythmique (Lausanne, 1916, p. 35-36), Dalcroze descreve seis maneiras de saltitar, apresentando, para cada uma delas, uma figura específica desenhada pelo mítico Paulet Thévenaz. Em termos técnicos, esses saltitos são equivalentes ao "temps levé" do balé clássico.
} 
8. Os alunos caminham as semicolcheias. Uma duína tocada ao piano (ou tercina ou quartina etc.) impulsiona 2, 3 ou 4 passos mais curtos no tempo seguinte.

9. Ao final de uma série de semicolcheias, uma quartina determina uma métrica de 4 tempos; uma sextina, uma métrica a 6 tempos etc.

10. Um accelerando de um compasso determina que a execução do tema seja feita duas vezes mais rápido; um ritenuto provoca uma execução duas vezes mais lenta.

11. Uma série de ritmos legato provoca uma interpretação de movimentos contínuos; o staccato modifica a interpretação.

12. Durante uma cadência (cânone), o aluno executa, um compasso depois do piano, nuances em relação ao compasso que acabou de ser tocado. Ou ainda, ele interpreta o compasso que está caminhando, no compasso seguinte, com as nuances tocadas ao piano.

13. Uma síncope por antecipação provoca um atraso no tempo seguinte, e o contrário.

\section{Melodia e harmonia}

1. Uma série ascendente de 4 graus conjuntos faz o aluno caminhar para a frente; uma série descendente o faz caminhar para trás.

2. Depois de várias repetições da tônica de uma escala, um ataque sobre o III grau indica que se deve caminhar em tercinas o compasso seguinte etc.

3. Depois de várias repetições de um intervalo qualquer, os alunos devem atacar um compasso composto durante o tempo em que o intervalo ressoar ou então correr esse tempo em colcheias.

4. Os tons inteiros indicam um caminhar para a frente, os semitons indicam um caminhar no mesmo lugar (ou passos bem pequenos).

5. Uma apogiatura inferior indica a execução de um gesto para cima, uma apogiatura superior provoca um gesto para baixo ou para trás.

6. Acordes tocados no registro médio do piano incitam o aluno a caminhar em semínimas; no agudo, devem correr em colcheias, no grave, devem bater os pés etc., ou ainda realizar gestos nas 3 regiões da altura². 
7. Acordes maiores provocam a elevação dos braços, os menores a flexão do torso e dos joelhos; acordes de sétima maior uma parada, de nona uma genuflexão etc., etc.

8. Uma melodia a duas vozes faz os alunos caminharem em duas fileiras, uma melodia a 3 ou 4 vozes faz com que caminhem em 3 ou 4 fileiras.

9. Uma modulação modifica a direção do caminhar ou da atitude.

10. O ataque brusco de um acorde modulante obriga o aluno a realizar um salto ou mudar de direção.

11. Ao final de uma série de acordes tocados ao piano, o aluno busca reconhecer o grau constituído pelo último acorde. Ele faz um agachamento ou um gesto no plano ${ }^{3}$ correspondente ao grau (por exemplo, o acorde de VI o faz realizar um agachamento no plano 6).

12. O mesmo exercício anterior, mas realizando o $6^{\circ}$ saltito $^{4}$ ao ouvir o acorde de VI etc.

13. Depois de um grupeto de um ou outro tipo (do-ré-do-si-do ou do-si-do-ré-do ou do-si-do-si-do ou do-ré-do-ré-do etc., etc.), realizar uma pirueta, um salto, um saltito, uma flexão do torso etc.

14. A queda de um fraseado melódico provoca a mudança de direção do caminhar ou do gesto, ou uma mudança no tônus muscular.

15. O aluno contrapõe a semibreve por 8 colcheias, a mínima pontuada por 3 saltitos, a mínima por uma genuflexão, a semínima por uma parada ou um salto. As variações são infinitas. Ao piano, uma cadência.

16. O professor toca uma melodia em contraponto com colcheias exatas. Uma fileira realiza a melodia e a outra, o contraponto. Assim que o professor inverte a estrutura, os alunos trocam de voz.

17. O professor, ao tocar a duas vozes em estilo clássico, introduz uma dissonância; o aluno a resolve corporalmente realizando um passo para trás etc.

2 Essas regiões indicam os níveis espaciais da altura, a saber: alto, médio e baixo.

3 Dalcroze não faz qualquer menção à "planos" em nenhum dos dois volumes do caderno didático La Rythmique. Essa relação entre os "planos" e as funções harmônicas parece ser uma referência aos "graus de orientação espacial" indicados no primeiro volume de La Rythmique (Lausanne, 1916, p. 9), combinados aos "intervalos e acordes" descritos no segundo volume (Lausanne, 1917, p. 56).

4 Vide nota $n^{\circ} .1$. 
18. Um desenho ascendente provoca um salto para frente; um desenho descendente, um salto para trás; um trilo com apogiatura inferior, um salto à esquerda; um trilo com apogiatura superior, um salto à direita.

19. Os alunos caminham em determinado andamento ou ritmo enquanto o professor repete um acorde ao piano. No momento em que ele introduz uma alteração, os alunos mudam o andamento ou o ritmo.

20. O mesmo exercício anterior substituindo a alteração por uma mudança de posição ou inversão, ou ainda por uma mudança na sétima (acordes de um determinado grau ou de outro).

\section{Rítmica e métrica}

1. As mudanças no caminhar, no salto, na atitude, na acentuação etc., são definidas pelas mudanças de um determinado ritmo ou mudanças de métrica.

2. Depois de uma pausa de um tempo, o aluno realiza um saltito; uma pausa de dois tempos, dois saltitos etc., ou ainda uma genuflexão.

3. As síncopes tocadas ao piano fazem o aluno caminhar nos tempos, e o contrário.

4. Assim que o professor toca as mínimas, o aluno realiza determinado ritmo, ao passo que uma mínima pontuada (ou uma semibreve) provoca um ritmo diferente.

5. Uma anacruse ascendente faz o aluno caminhar para frente, uma anacruse descendente o faz caminhar para trás.

6. Tendo apresentado de 3 a 4 ritmos anacrústicos estudados de antemão, os alunos, durante uma improvisação, interrompem os movimentos para realizar o ritmo anacrústico identificado que foi inesperadamente tocado pelo professor.

7. Os alunos caminham em semínimas enquanto o professor toca semínimas em uníssono. Assim que a mão direita toca um ritmo curto (tercina, sautillé ${ }^{5}$ etc.), os alunos caminham esse ritmo para frente; do mesmo modo que eles devem caminhar para trás se o ritmo é tocado no registro grave.

8. Tendo apresentado uma sequência conhecida de 4 compassos, o aluno executa o primeiro enquanto ouve o segundo, o segundo enquanto ouve o terceiro etc., etc.

\footnotetext{
5 "Sautillé", literalmente "saltito", é um termo técnico referente ao manejo do arco nos instrumentos de cordas friccionadas (golpes de arco) e que produz uma articulação específica, muito virtuosística. No contexto do exercício, Dalcroze está sugerindo uma figura rítmica curta que sugira um saltito.
} 


\section{Timbres}

1. O professor toca e canta determinados ritmos de forma alternada e arbitrariamente. $O$ aluno realiza-os de certo modo quando são cantados e de outro modo quando são tocados. A mesma coisa, cantando alternadamente vozes diversas.

2. O mesmo exercício, mas os temas são tocados alternadamente no piano e em um, dois ou três instrumentos de percussão.

3. Um toque de baqueta em um tambor impulsiona um saltito, em um címbalo, uma pirueta, em um triângulo, uma suspensão, em um tímpano, uma genuflexão, na madeira do tambor, um salto etc. etc.

4. Um toque de baqueta em um bumbo indica a parada brusca de uma corrida, dois toques rápidos no tambor provocam a realização de duas duínas, o caminhar durante um compasso binário ou duas ou quatro vezes mais lento.

5. Dois toques desferidos simultaneamente sobre 2 instrumentos de percussão (um tambor e um triângulo, por exemplo) provocam no aluno determinado ritmo corporal, enquanto outro aluno se junta a ele acrescentando um outro ritmo. A mesma coisa a 3 vozes.

6. Seguir caminhando o rubato de um instrumento, e gesticulando (ou tocando um pandeiro) o rubato de um outro instrumento.

\section{Sensação e análise visual}

1. Um determinado gesto previamente combinado e executado por um solista faz com que os alunos caminhem em um determinado ritmo. Um outro gesto impulsiona um ritmo diferente.

2. Um gesto realizado por um solista interrompe uma corrida ou uma série de saltos.

3. Um círculo de 4 ou 5 pessoas evolui realizando as mesmas figuras ditadas por um solista que caminha ou que desenha essas figuras sobre o quadro negro.

4. Uma interrupção ou mudança de luz determina uma dada atitude ou outra.

5. Alternâncias entre luz e escuridão determinam mudanças de métrica ou ritmo.

6. O aluno, caminhando no mesmo lugar, realiza o ritmo ou a métrica indicada por um solista, enquanto ele interpreta com os braços os ritmos indicados por um segundo solista posicionado ao lado do primeiro. 
7. O aluno percute com a mão direita, de forma regular, a métrica indicada por um solista e com a mão esquerda o rubato de um segundo solista.

8. Tendo sido apresentados de antemão 4 a 5 ritmos diferentes, o aluno combina-os na sequência indicada através de apresentações com 4 ou 5 tecidos ou papéis coloridos. 